\title{
Experimental investigations and multi criteria optimization during machining of A356/WC MMCs using EDM
}

\author{
Akash Singh $^{\mathrm{a}}$, Karan Kumara ${ }^{\mathrm{a}}$, K. Gnana Sundari ${ }^{\mathrm{b}}$, Rishitosh Ranjana and B. Surekha ${ }^{\mathrm{a}^{*}}$
}

${ }^{a}$ School of Mechanical Engineering, Kalinga Institute of Industrial Technology, Odisha, India-751024

${ }^{b}$ Department of Mechanical Engineering, Karunya Institute of Technology \& Sciences, Tamilnadu, India-641114

\section{H R O N I C L E}

Article history:

Received August 1, 2021

Received in revised format:

November 10, 2021

Accepted December 12021

Available online

December 2, 2021

Keywords:

Electric discharge machine

Tungsten carbide

Al alloy

Grey regression analysis

Response surface methodology

\begin{abstract}
A B S T R A C T
In the current paper, the authors are intended to manufacture the aluminum based metal matrix composite (MMC) employing the stir casting process. Further, the fabricated composite sample is investigated for machining characteristics during the die sink electrical discharge machining process (EDM). EDM is most commonly employed to satisfy the special needs of industry such as developing deep holes and complex contours from high strength materials such as composites, alloys, smart materials, and functionally graded materials. In the current study A356 and 4\%, tungsten carbide (WC) powder are considered as matrix and strengthening materials respectively to fabricate the MMCs. During the machining activity, the input factors like discharge current $\left(\mathrm{I}_{\mathrm{p}}\right)$, Voltage $\left(\mathrm{V}_{\mathrm{g}}\right)$, Pulse On-Time $\left(\mathrm{T}_{\mathrm{on}}\right)$, and flushing pressure $(\mathrm{P})$ are optimized for achieving optimum surface roughness (SR), Tool Wear Rate (TWR) and Material Removal Rate (MRR). To estimate the ideal set of process factors grey regression analysis (GRA) is used. From the results, it was observed that the GRA is found to perform better than the RSM.
\end{abstract}

\section{Introduction}

In the present scenario, the existing monolithic materials fail to provide the amenable properties together at a time. Therefore, it is desirable to have some extensions and modifications in pre-existing materials to meet the desirable properties for better efficiency and performance. MMCs are formed by mixing two or more dissimilar materials to create a unique material. Aluminum alloys are heavily adapted by the automobile industries and aeronautics industries due to their excellent features like high stiffness, specific strength, low density, and low coefficient of thermal expansion. The ease of fabrication, and high rigidity coupled with specific strength are important for the space and missile applications (Dwivedi et al., 2014). When WC is added to aluminum it leads to the formation of aluminium Metal Matrix Composites (AMMC) which are known for lightweight and high-performance aluminum centric materials and they have a better demand due to their properties like reduced density, higher strength, and better features at high temperature. There are various MMCs like $\mathrm{Al} / \mathrm{Sic}, \mathrm{Al} / \mathrm{TiC}$ (Kandpal \& Singh, 2015). The combination of WC and aluminum enhances the impact property of the strengthened aluminum by minimizing voids and cracks (Rohith et al., 2018). Electrical discharge machining i.e. EDM also called spark machining, die sinking, burning and spark eroding is a well-acknowledged material removal activity suited to fabricate the engineering parts which are tough to machine by any of the traditional machining activity and have challenging form and shape. EDM can be used to control parameters to attain the desired dimensional accuracy. EDM is used to make intricate profiles on any electrically conductive material without being affected by the material's hardness and toughness. EDM processes are of several types like micro EDM, wire EDM, dry EDM, sinking EDM, powder mixed EDM, and hybrid EDM. The machining is done by attaining continuous-discrete discharges in between the cathode which is the electrode

* Corresponding author.

E-mail address: surekhafme@kiit.ac.in (B. Surekha)

(C) 2022 by the authors; licensee Growing Science, Canada.

doi: $10.5267 /$ dsl.2021.12.001 
wire tool and a workpiece (anode), which is separated by a dielectric fluid medium. The elimination of material occurred by melting and subsequent vaporization of the melted metal in the presence of the dielectric material. The tool used was a brass tool of diameter $9 \mathrm{~mm}$. The workpiece was aluminum alloy (A356) strengthened with tungsten carbide (WC). The objective of the authors is to use discharge current $\left(\mathrm{I}_{\mathrm{p}}\right)$ in amperes, voltage $\left(\mathrm{V}_{\mathrm{r}}\right)$ in volts, flushing pressure $(\mathrm{P})$, and pulse ontime $\left(\mathrm{T}_{\mathrm{on}}\right)$ as the contribution factors for optimization to achieve maximum MRR, minimal TWR and also to find surface roughness. Stir casting is the most commonly utilized techniques to create MMCs with reinforcements. The particle distribution is influenced by the holding time during stir casting (Krishna et al., 2018). Using stir casting, a metal matrix composite was cast with A356 and 4\% WC. Sharma et. al. (2020) said that composites are being used since the earliest of the advanced stages in human development for various purposes and the requirement of metal matrix composites (MMCs) saw a significant increase as people kept on finding new uses for them. It has also been seen as a growing trend in the industries to develop lightweight materials which are stronger having better efficiency and performance and can be used in a variety of different situations. Because of this Aluminium Metal Matrix Composites (AMMCs) are a big asset to the industry. AMMCs provide wide applications and can be reinforced with several reinforcing materials. By stir casting, Siddanna \& Devoor, (2016) cast LM 25 aluminum alloy and proposed that impact testing and micro hardness testing be carried out to assess their mechanical properties. Jagtap (2016) tested that EDM can machine hard materials which are hard to cut. As a dielectric medium, hydrocarbon oils and distilled water were used, resulting in higher MR levels and lower TW levels. Zang et. al.(2014) studied the effects of dielectric gasses and liquids, such as deionized water, oxygen, kerosene and air. The morphology of dips and recast layers was also analyzed, and the characteristic of material removal was also related to the discharge pulse via simulation. Niamat et. al. (2017) performed a comparative analysis on the processing of Al6061 alloy electric discharge with distilled water, and kerosene as a dielectric material. It was analyzed that kerosene in aluminum mixed EDM gives a better machining quality than distilled water. Shehata et. al. (2016) executed an investigation of the Al / $\mathrm{SiC}$ composite by taking kerosene and paraffin oil as a dielectric medium. More MMR, lower TWR, and better surface texture were observed for kerosene as compared to paraffin oil. Analyzed the dielectric directly influences the specimen's surface properties. Kumar et. al. (2018) experimented to reduce the several difficulties associated with machining aluminum metal matrix composites. Taking into account collective material and WEDM parameters, AMMC samples are generated according to the Taguchi experimental design and are machined to get the individual outputs: surface irregularity and kerf width. Those are evaluated and interpreted with the patronage of a fuzzy method, an optimum set of parameters. Lata et. al. (2018) studied aluminum which was reinforced with $\mathrm{TiO}_{2}$ and investigated the mechanical properties. Their research found with the upsurge in the quantity of $\mathrm{TiO}_{2}$ the mechanical properties studied by them enhanced. Kumar et. al. (2019) prepared two specimens, one of them being $\mathrm{Al}$ (6351)-SiC and the other one being $\mathrm{Al}$ (6351)-SiC-B ${ }_{4} \mathrm{C}$, and machined it with electric discharge machining and investigated the surface characteristics. The reinforcement with SiC showed a better removal rate of material and an increase in heat affect zone also known as HAZ. Further, it was noticed that with the added reinforcement of $\mathrm{B}_{4} \mathrm{C}$, the composite showed more signs of defects. Dhupal et al., (2018) optimized the Al-Sic process through EDM using two different electrodes one of them being brass and noted that with the brass electrode, MRR is more at a upper value of current and gap voltage. Dhas et al., (2019) fabricated two aluminum hybrid matrixes using the melt stir casting method, one of them was AA5052 reinforced with graphite particles and WC, and the second one was AA5052 strengthened with $\mathrm{SiC}$ and reinforced with graphite elements. They found that the mechanical properties they studied were better in the case of AA5052 strengthened with graphite particles and WC as compared with AA5052 strengthened with SiC and graphite particles. Kumar et al., (2018) also manufactured an aluminum hybrid matrix. They fabricated A17075 alloys reinforced with varying concentrations of $\mathrm{TiC}$ and graphite, and studied microstructures, mechanical and wear characteristics. They concluded that an increase in the concentration of the reinforcements leads to better mechanical properties and better wear resistance along with better microstructural properties. Markopolos et al., (2019) examined the machining of aluminum alloy A15052 using EDM with changing parameters $\mathrm{I}_{\mathrm{p}}$ and $\mathrm{T}_{\text {on }}$ and as output MRR, Ra, HAZ were observed and made a conclusion that MRR is mostly affected by Ip and the machined surface roughness depends on $\mathrm{I}_{\mathrm{p}}$. Srivastava (2020) developed an aluminum 6063 metal matrix by reinforcing it with 5\% SiC to investigate the mechanical characterizations and also to examine the machinability behaviour of the metal matrix composite produced using EDM. They found that process factors influence the MMR significantly and the calculated optimum process factors improved MRR by $37.5 \%$. Palanisamy et al., (2020) improved the EDM process variables namely discharge current, Pulse Off-Time, and Pulse OnTime to have a better MRR and lesser surface irregularity and wear rate of the tool. To experiment with the stir cast LM6Alumina as a metal matrix composite. They found that the most influential of the input parameters were the discharge current. Kar et al., (2018) studied Al7075 as a matrix and reinforced it with 6\% by weight-red mud. They found during the EDM process that the discharge current and pulse on-time influence the machining characteristics of the aluminum metal matrix quite significantly. Malhotra al. (2020) fabricated a hybrid metal matrix composite with A17075 and reinforced it with nanoparticles of Magnesium and $10 \% \mathrm{SiC}$ (Silicon Carbide) using stir casting method. The experiment was directed to examine the influence of input process factors on the material removal rate and rate of wear of the electrode. They did a comparative evaluation of conventional electric discharge machining and rotatory electric discharge machining. They found that the rotatory EDM process yielded better results and it had a greater MRR and lesser EWR as matched to conventional electric discharge machining. Kumar et al., (2020) synthesized two specimens, one of them being AA2024 reinforced with silicon dioxide $\left(\mathrm{SiO}_{2}\right)$ Nano powder $2 \%$ by weight and the other one being AA2024 reinforced with silicon dioxide $(\mathrm{SiO})$ Nano powder 3\% by weight. They experimented to compare the machining characteristics of AA2024 to the synthesized specimens. These machining characters include the removal rate of material (MRR), the wear rate of the tool (TWR), and surface irregularity (SR). They found that after the reinforcement of silicon dioxide Nano powder, the prepared specimens 
have a lesser material removal rate whereas the tool wear rate and surface roughness increase. Chandramouli \& Eswaraiah (2017) experimented on steel alloy and investigated the optimum electric discharge machining (EDM) process factors and the effect they had on the material removal rate (MRR), the wear rate of tool (TWR) and surface roughness. The input parameters were takes as tool lift, pulse off-time, pulse on-time and current. They identified that the two parameters had a more significant impact on machining characteristics than the rest. In the case of TWR, it was detected that the tool lift was a very important part and it was concluded as the prevailing feature. In the case of MRR and SR, it was found that the discharge current was the dominant factor. They also found that the specimen created had a higher MRR and lower TWR. Raju \& Balakrishnan (2020) fabricated A16061 strengthened with 10\% by weight fraction of boron carbide by stir casting and investigated the optimum parameters to get a better rate of material removal and a better surface finish. The experiment conducted used wire electric discharge machining and used pulse on-time, discharge current and pulse off-time as process parameters. The results of their experiment showed that current and pulse on time were the dominant factors. They noticed that when the process parameters had an increase in values it resulted in a better removal rate of material and had a smoother surface finish. Kandpal et. al. (2018) used the nonconventional machining technique of electric discharge machining to machine aluminum alloy AA6061 reinforced with 10\% by weight A12O3. They optimized the input parameters and recorded the output response as material removal rate. They concluded that MRR increases with the increment of pulse on-time and gap current. Venkatesan \& Xavior (2019), using liquid metallurgy techniques like squeeze casting and stir casting developed composites of AA7050 matrix reinforced with graphene nanoparticles. Stirring speed, melting temperature, and graphene content is taken as experimental parameters. Taguchi's L27 orthogonal array was used by them to assess the composite's tensile strength, yield strength, and resistance to scratch. They concluded that the content of graphene was the dominant factor influencing the output responses in the case of stir casting but in the case of squeeze casting the dominant factor was melting temperature. Talla et. al. (2015) attempted to fabricate an aluminum metal matrix composite using electric discharge machining also called EDM by adding aluminum powder in the dielectric namely, kerosene. It was found that the composite had a higher material removal rate and a smoother surface as compared to conventional electric discharge machining. Tharian et.al. (2019) Conducted a multi-objective optimization on aluminium alloy A17075 during EDM. The input parameters were Pulse Off-time, Pulse On-time, federate and peak current. Optimization of the performance measures Material Removal rate (MRR) and Surface Roughness (SR) was done using Taguchi method in single-objective, optimization and later GRA is used for multi-objective optimization to find significant parameters affecting SR and MRR. Shukla and Shukla \& Dhakad (2018), performed a multi-response optimization through GRA for Al-LM6 aluminum alloy with varying weight of $\mathrm{SiC}$ and $\mathrm{B} 4 \mathrm{C}$ cast using stir casting machined with EDM. The objective of the paper was to optimize the responses like Material Removal Rate (MRR), Tool Wear Rate (TWR), and Radial over Cut (ROC), and flatness. They found out that in comparison with the input parameters composition, duty factor, Pulse On-Time, Current contributes more towards the output of responses. Sakthivelu et. al. (2020) cast AA7075-SiC composites using stir casting technique and optimized the parameters current, pulse on-time and voltage for the machining of the composites in EDM for the response Surface Roughness and Material Removal Rate using Taguchi optimization technique and found that current was the most influencing parameter for minimum surface roughness and voltage plays the vital role in maximum MRR. Dey et.al. (2021) conducted EDM on the Al-based composites fabricated using the compo casting process. They found that the pulse on time and peak current are the most important parameters of MRR and TWR. Further, the desirability function was used to predict the optimal set of parameters. Panda et. al. (2015) made an attempt to establish the inter relationship between various input and output parameters during EDM process. Further, particle swarm optimization algorithm was adopted to estimate the optimum set of variables.

In the current research, the investigators gave an effort to fabricate the A356/WC MMC and to estimate the optimal set of parameters during electric discharge machining of the fabricated specimen. Experimentations are accomplished using response surface methodology by considering peak current, gap voltage, and pulse on time, and flushing pressure as process variables. Surface roughness, tool wear rate, and material removal rate are considered as responses. The uniqueness of this script lies in studying the machinability characteristics of the fabricated A356/WC MMCs using electro-discharge machining (EDM). Further, an attempt is made to accomplish multi criterion optimization using GRA

\section{Experiment Details}

In this research, aluminum-tungsten carbide MMC is made utilizing stir casting technique with A356 and $4 \%$ of tungsten carbide as matrix and strengthening constituents respectively. Furthermore, the process modeling and optimization of the electric discharge machining method have been conducted.

\subsection{Fabrication of the specimen}

The A356-WC metal matrix composite is manufactured using the stir casting technique. Initially, the aluminum alloy is converted to molten metal by heating up to $720 \mathrm{oC}$ in an electric furnace. Once the molten metal is formed the preheated WC particles of $15 \mu \mathrm{m}$ were added to the melt. For the even dispersal of the added strengthening elements, a mechanical stirrer is used at a speed of $250 \mathrm{rpm}$. The stirring is continued for 1 minute and after 2 minutes again stirring is done for further mixing of the matrix and reinforcing material. This stirring is repeated for 1 minute at an interval of 2 minutes 3 times. For the fabrication of the MMC, a rectangular die with a cavity of dimensions $10 \mathrm{X} 6 \mathrm{X} 5 \mathrm{~cm} 3 \mathrm{has}$ been used. Once the uniform molten mixture is formed after stirring, it is emptied into the pre-heated die and allows for solidification. De- 
gasifier such as sodium hexafluoroaluminate is added to the melt to minimize the gas defects in the casting specimen. Fig. 1 and Fig. 2 are showing the stir casting setup and pouring of melt into the die respectively.

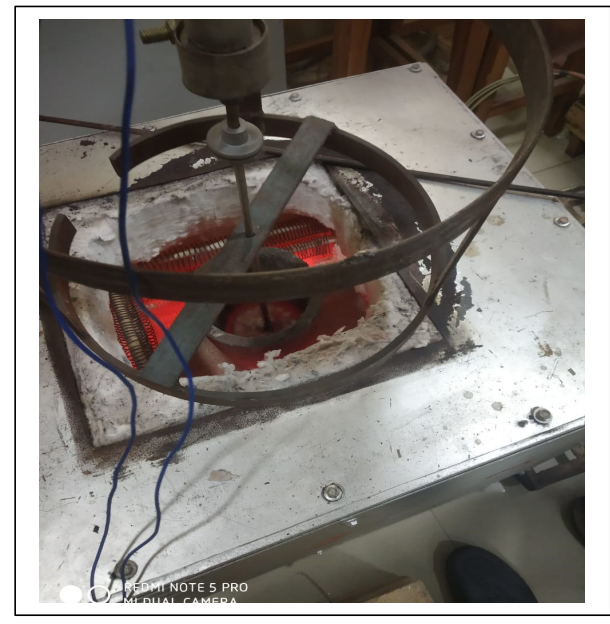

Fig. 1. Stirring of molten metal mixture

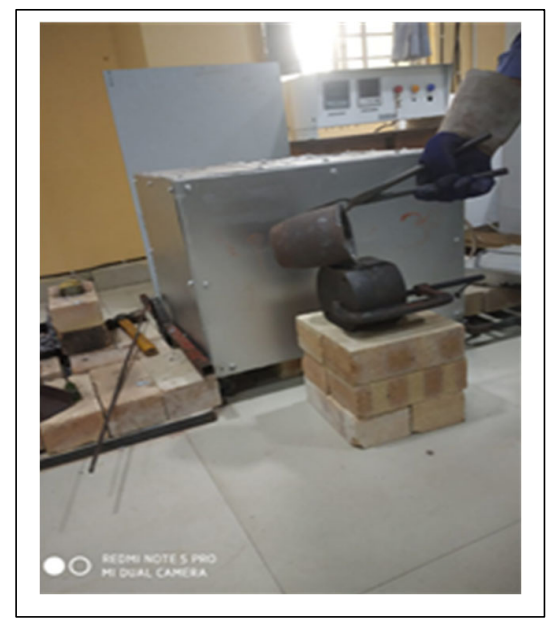

Fig. 2. Pouring the molten metal into the die

\subsection{Electric discharge machining of $M M C$ using $D O E$}

After the AMMC is fabricated, its machining features are being examined in the EDM process. From the literature, it is detected that several materials have been machined using EDM to study the machining characteristics. The EDM utilized for the experimentation is made by ELECTRONICA -SMART ZNC showed in Fig. 3. The polarity of the workpiece and electrode are set as negative and positive, respectively. Kerosene is utilized as the dielectric medium because of its low density and viscosity. It has a dielectric constant of 1.8 and a flashpoint of 38 degrees centigrade. The fabricated Al-based MMC is used as a work piece and a $10 \mathrm{~mm}$ diameter brass rod is considered as the tool (ref. Fig. 4).

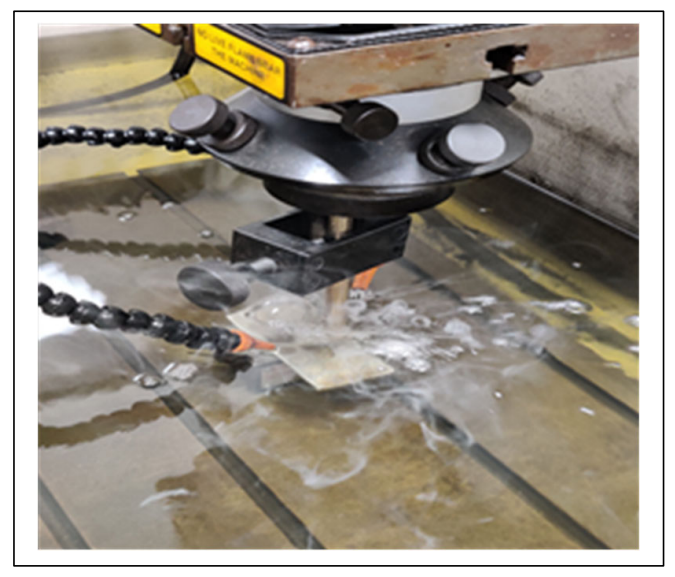

Fig. 3. Schematic showing Machining in EDM
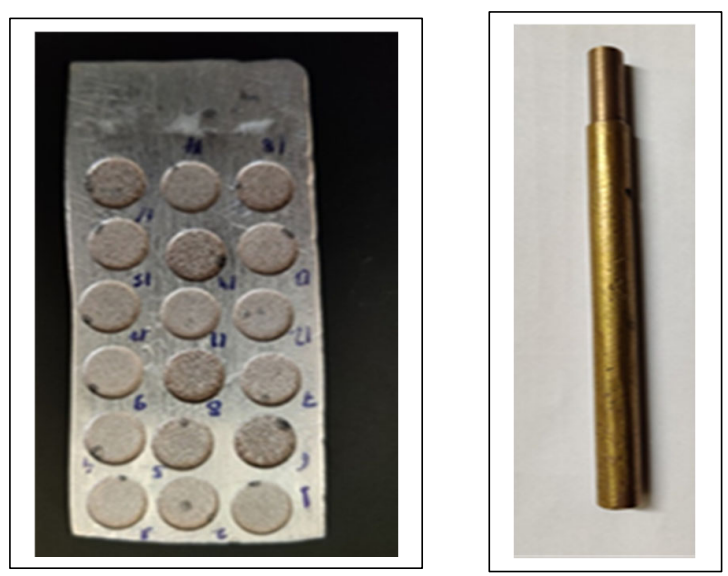

Fig. 4. Schematic of (a) work piece (b) Brass electrod

The set of experiments need to carried out is acquired by utilizing response surface methodology (RSM). From the literature, it can be observed that the parameters like pulse on time $\left(\mathrm{T}_{\text {on }}\right)$, peak current $\left(\mathrm{I}_{\mathrm{p}}\right)$, Gap voltage $(\mathrm{V})$ and the flushing pressure $(\mathrm{P})$, duty factor in $\%$ have a very deciding effect on the machining outcomes like surface roughness (SR), tool wear rate (TWR), material removal rate (MRR), and radial overcut (ROC). In the current research, the authors have selected flushing pressure $(\mathrm{P})$, gap voltage $(\mathrm{V})$, peak current $\left(\mathrm{I}_{\mathrm{p}}\right)$, and the pulse on time $\left(\mathrm{T}_{\mathrm{on}}\right)$ are taken as input factors and material removal rate (MRR), tool wear rate (TWR) and surface roughness (SR) as outcomes. At the beginning, it is required to decide the range of process variables concerning the machine specifications, literature and by conducting pilot experimentation. After finalizing the levels of process factors, the experiments are performed based on the central composite design of experiments. In the current script, MINITAB software is utilized to scrutinize the design of experiments. Table 1 shows the input factors along with their levels considered for the experimental investigations. Once the machining is completed the outputs such as MRR, TWR and SR are calculated using the following expressions. 
Table 1

Levels of input factors

\begin{tabular}{lllll}
\hline Machining parameters & Symbol & Low level $(-1)$ & Medium level $(0)$ & High level $(+1)$ \\
\hline Peak current $(\mathrm{Amp})$ & $\mathrm{I}_{\mathrm{p}}$ & 10 & 15 & 20 \\
Pulse on time $(\mathrm{ms})$ & $\mathrm{T}_{\text {on }}$ & 50 & 100 & 150 \\
Gap voltage $($ volts) & $\mathrm{V}_{\mathrm{g}}$ & 40 & 50 & 60 \\
Flushing Pressure $\left(\mathrm{kg} / \mathrm{cm}^{2}\right)$ & $\mathrm{P}$ & 0.5 & 1.0 & 1.5 \\
\hline
\end{tabular}

$M R R=\left(W_{b}-W_{a}\right) / t$

where $\mathrm{W}_{\mathrm{b}}$ and $\mathrm{W}_{\mathrm{a}}$ are the weight of the workpiece before and after each machining and $\mathrm{t}$ is the machining time for each impression. Moreover, TWR is calculated using Eq. (2),

$$
T W R=\left(T_{b}-T_{a}\right) / t
$$

where $T_{a}$ and $T_{b}$ are the weight of the tool after and before processing in gram and $t$ is the machining time for each impression. Further surface roughness is calculated using $\mathrm{R}_{\mathrm{a}}$ in $\mathrm{mm}$ which is directly measured by surface roughness testing machine by taking $7.5 \mathrm{~mm}$ of the workpiece with 3 runs each and the $R_{a}$ is the average of the 3 runs. Table 2 . Shows the design of experiments along with the responses.

$$
R_{a}=\left(R_{a 1}+R_{a 2}+R_{a 3}\right) / 3
$$

where $R_{a 1}, R_{a 2}, R_{a 3}$ are the surface roughness of the workpiece in each run.

Table 2

\begin{tabular}{|c|c|c|c|c|c|c|c|}
\hline Std Order & Ip & Vg & Ton & $\mathbf{P}$ & MRR & TWR & Ra \\
\hline 1 & 10 & 40 & 50 & 1 & 0.813665 & 0.403727 & 0.0038 \\
\hline 2 & 20 & 40 & 50 & 1 & 1.75 & 0.683333 & 0.0047 \\
\hline 3 & 10 & 60 & 50 & 1 & 0.480952 & 0.319048 & 0.004 \\
\hline 4 & 20 & 60 & 50 & 1 & 1.019417 & 0.446602 & 0.0045 \\
\hline 5 & 10 & 40 & 150 & 1 & 1.115385 & 0.461538 & 0.0061 \\
\hline 6 & 20 & 40 & 150 & 1 & 3.375 & 0.95 & 0.0075 \\
\hline 7 & 10 & 60 & 150 & 1 & 0.637 & 0.351563 & 0.0062 \\
\hline 8 & 20 & 60 & 150 & 1 & 1.614 & 0.55 & 0.0077 \\
\hline 9 & 10 & 40 & 50 & 2 & 0.341 & 0.283333 & 0.003992 \\
\hline 10 & 20 & 40 & 50 & 2 & 1.315068 & 0.643836 & 0.0046 \\
\hline 11 & 10 & 60 & 50 & 2 & 0.549738 & 0.2906 & 0.0034 \\
\hline 12 & 20 & 60 & 50 & 2 & 1.18 & 0.54 & 0.004372 \\
\hline 13 & 10 & 40 & 150 & 2 & 1.036036 & 0.369369 & 0.005706 \\
\hline 14 & 20 & 40 & 150 & 2 & 3.368421 & 0.894737 & 0.0079 \\
\hline 15 & 10 & 60 & 150 & 2 & 0.859259 & 0.37037 & 0.005857 \\
\hline 16 & 20 & 60 & 150 & 2 & 2.08 & 0.64 & 0.006905 \\
\hline 17 & 10 & 50 & 100 & 1.5 & 0.873874 & 0.405405 & 0.0054 \\
\hline 18 & 20 & 50 & 100 & 1.5 & 2.455 & 0.766 & 0.0069 \\
\hline 19 & 15 & 40 & 100 & 1.5 & 1.506849 & 0.616438 & 0.0061 \\
\hline 20 & 15 & 60 & 100 & 1.5 & 1.411765 & 0.502 & 0.0058 \\
\hline 21 & 15 & 50 & 50 & 1.5 & 1.173913 & 0.497 & 0.002817 \\
\hline 22 & 15 & 50 & 150 & 1.5 & 1.904762 & 0.58381 & 0.005673 \\
\hline 23 & 15 & 50 & 100 & 1 & 1.6875 & 0.640625 & 0.0059 \\
\hline 24 & 15 & 50 & 100 & 2 & 1.797297 & 0.594595 & 0.0057 \\
\hline 25 & 15 & 50 & 100 & 1.5 & 1.777778 & 0.6099 & 0.005737 \\
\hline 26 & 15 & 50 & 100 & 1.5 & 1.652174 & 0.596 & 0.0057 \\
\hline 27 & 15 & 50 & 100 & 1.5 & 1.652174 & 0.5782 & 0.0057 \\
\hline
\end{tabular}

The design matrix showing the levels of inputs and responses

\subsection{Multi objective optimization using Gray relational analysis}

In the present work, authors attempted to use a powerful multi-objective optimization tool namely, Grey relational analysis for optimizing the machining of A1356/WC MMCs during EDM. Initially, the investigational data is regularized between 0 and 1 to avoid the variances in the directions and intensities of various factors. The normalization of data is performed based on the quality characteristics of the data responses. The various types of the quality characteristics namely, larger the best' [refer to Eq. (4)], 'smaller the best' [refer to Eq. (5)], and 'nominal the best' [refer to Eq. (6)] (Zhang et al., 2014).

$$
F_{t}^{*}(l)=\frac{F_{t}^{0}(l)-F_{t}^{0}(l)_{\min }}{F_{t}^{0}(l)_{\max }-F_{t}^{0}(k)_{\min }}
$$




$$
\begin{aligned}
F_{t}^{*}(l) & =\frac{F_{t}^{0}(l)_{\max }-F_{t}^{0}(l)}{F_{t}^{0}(l)_{\max }-F_{t}^{0}(l)_{\min }}, \\
F_{t}^{*}(l) & =1-\frac{F_{t}^{0}(l)-T_{\mathrm{ov}}}{\max \left\{F_{t}^{0}(l)_{\max }-F_{t}^{0}(l)_{\max }, T_{\mathrm{ov}}-F_{t}^{0}(l)_{\min }\right\}},
\end{aligned}
$$

where,

$T_{\mathrm{ov}}, F_{t}^{0}(l)$ and $\max F_{t}^{0}(l)$ represents the optimum value, minimum and maximum values respectively of the optimal sequence $F_{t}^{0}(l)$. Further, $F_{t}^{*}(l)$ represent the comparable sequence of the original data. It is not that the GRC represents the relationship between the ideal results and normalized values of experimentally. The calculation of GRC is given in the following equation

$$
\eta_{t}(l)=\frac{\Delta_{\min }+\Upsilon \chi \Delta_{\max }}{\Delta_{o t}(l)+\Upsilon \chi \Delta_{\max }},
$$

where the distinguishing factor $Y$ is selected to be equal to 0.5 . Moreover, $\Delta_{o t}(l)$ indicates the deviation sequence. Once the GRC value is determined, it is used to find the Grey relational grade (GRG). Further, the GRG is utilized to determine the best comparability sequence, which is given below.

$$
\alpha_{t}=\frac{1}{m} \sum_{l=1}^{m} \eta_{t}(l) .
$$

\section{Result and Discussion}

The non-linear regression relationships obtained using MINITAB software for different responses namely MRR, TWR, and surface roughness ( $\mathrm{R}_{\mathrm{a})}$ are given in Eqn. (4), (5), and (6), respectively.

$$
\begin{aligned}
& M R R=-6.44+0.241 I p+0.258 \mathrm{Vg}+0.0183 \mathrm{Ton}-2.34 P-0.00092 \mathrm{I} p * I-0.00228 \mathrm{Vg} \\
& * V g-0.000059 \text { Ton } * \text { Ton }+0.220 P * P-0.003920 I p * V g+0.000928 I p \\
& * \text { Ton }+0.0112 \mathrm{Ip} * P-0.000339 \mathrm{Vg} * \text { Ton }+0.02389 \mathrm{Vg} * P+0.00320 \text { Ton } * P \\
& T W R=-0.831+0.0721 I p+0.0407 \mathrm{Vg}+0.00589 \mathrm{Ton}-0.703 P-0.000436 \mathrm{Ip} * I p \\
& -0.000374 \mathrm{Vg} * \mathrm{Vg}-0.000022 \mathrm{Ton} * \mathrm{Ton}+0.0840 P * P-0.001011 \mathrm{Ip} * \mathrm{Vg}+0.000116 \mathrm{Ip} * \\
& \text { Ton }+0.00777 \mathrm{Ip} * P-0.000043 \mathrm{Vg} * \text { Ton }+0.00601 \mathrm{Vg} * P+0.000141 \mathrm{Ton} * P \\
& R a=0.01164-0.000596 I p-0.000325 \mathrm{Vg}+0.000121 \mathrm{Ton}-0.00169 P+0.000023 \mathrm{I} p * I p \\
& +0.000004 \mathrm{Vg} * V g-0.000001 \mathrm{Ton} * \text { Ton }+0.000877 P * P-0.000001 \mathrm{Ip} * V g \\
& +0.000001 \mathrm{I} p * \text { Ton }+0.000013 \mathrm{I} p * P+0.000000 \mathrm{Vg} * \text { Ton }-0.000025 \mathrm{Vg} * P \\
& -0.000001 \text { Ton } * P
\end{aligned}
$$

3.1 Influence of process parameters on material removal rate (MRR)

To determine the effect of peak current, gap voltage, pulse on time, and flushing pressure, an analysis of variance (ANOVA) has been conducted. The results of ANOVA for material removal rate, electrode wear rate, and surface roughness are shown in Tables 3-5. The analysis was carried out at a 5\% significance level and $95 \%$ confidence level. From the results of ANOVA, it is observed that all individual, combined, and the square terms of the process parameters are having an influence on the MRR except the flushing pressure and the combined effect of gap voltage and flushing pressure. From the ANOVA results of TWR, it is noticed that except flushing term and square term of gap voltage rest all terms are influencing TWR. The ANOVA of SR reveals that all the terms are having an impact while predicting SR except the combined term of gap voltage and flushing pressure. It is to note that the lower levels of peak current and gap voltage, the energy available for the material removal is less and leads to poor MRR. In contrast, with the increased levels of the said parameters, the available higher energy may lead to a short circuit in the machining zone resulting in lower MRR. Therefore, ideal values of peak current and gap voltage are essential to produce high MRR. Fig. 5 displays the 3D surface plots represent the effect of peak current, gap voltage, pulse on time, and flushing pressure on MRR. Fig. 5(a) show the effect of peak current and gap voltage on MRR. The increase in MRR is observed with the increase in peak current and gap voltage. The increase in the pulse on time is directly proportional to the available energy for the machining which leads to an increase in MRR (ref Fig. 5(b)). The increase in the flushing pressure removes the burs formed during machining and increasing MRR (ref. Fig. 5(c)). From Fig. 5(d), 5(e) and 5(f)), the increase in the values of gap voltage, pulse on time, and flushing pressure resulting in an increase in the MRR due to the availability of high discharge for a longer time. Further, the increase in flushing pressure helps in the quick removal of burs at the machining zone (Srivastava, 2020). 


\subsection{Influence of process parameters on tool wear rate (TWR)}

The electrode wear rate is altering at different levels of the process parameters such as peak current, gap voltage, pulse on time, and flushing pressure. The influence of parameters on TWR is shown in Fig. (6). It is to be noted that the increase in peak current and gap voltage leads higher amount of discharge energy at the machining zone which will increase the material removal from the workpiece as well as a tool. A similar effect is found in Fig. 6(a). Further, the increase in pulse on time and flushing pressure along with raise in peak current increases the tool wear (ref. Fig. 6(b) and 6(c)). This may be because the increase in the sparking time and quick removal of burs by the increase in pulse on time and flushing pressure respectively, may lead to an increase in MRR. A similar effect is found in Fig. 6(d) and 6(c), with an increase in gap voltage along with an increase in pulse on time and flushing pressure. It is also found that the increase in both flushing pressure and pulse on time resulting in higher TWR. This is because the increase in pulse on time increases the supply of voltage for a long time which leads to increase the sparking time as well as the increase in flushing pressure results quick removal of burrs that helps to avoid short circuit at the machining zone.

Table 3

Analysis of variance table for MRR

\begin{tabular}{|c|c|c|c|c|c|}
\hline Source & DF & Adj SS & Adj MS & F-Value & P-Value \\
\hline Model & 14 & 14.4794 & 1.03424 & 33.77 & 0.0012 \\
\hline Linear & 4 & 11.5722 & 2.89306 & 94.47 & 0.002 \\
\hline Ip & 1 & 7.2835 & 7.28347 & 237.83 & 0.001 \\
\hline $\mathrm{Vg}$ & 1 & 1.2743 & 1.2743 & 41.61 & 0.0001 \\
\hline Ton & 1 & 3.0144 & 3.01442 & 98.43 & 0.0023 \\
\hline $\mathrm{P}$ & 1 & 0.0001 & 0.00006 & 0 & 0.064 \\
\hline Square & 4 & 0.6281 & 0.15702 & 5.13 & 0.012 \\
\hline Ip*Ip & 1 & 0.0014 & 0.00135 & 0.04 & 0.037 \\
\hline $\mathrm{Vg} * \mathrm{Vg}$ & 1 & 0.1337 & 0.13373 & 4.37 & 0.049 \\
\hline Ton*Ton & 1 & 0.0563 & 0.05634 & 1.84 & 0.002 \\
\hline $\mathrm{P} * \mathrm{P}$ & 1 & 0.0078 & 0.00779 & 0.25 & 0.023 \\
\hline 2-Way Interaction & 6 & 2.2791 & 0.37984 & 12.4 & 0.001 \\
\hline $\mathrm{Ip} * \mathrm{Vg}$ & 1 & 0.6146 & 0.61463 & 20.07 & 0.001 \\
\hline Ip*Ton & 1 & 0.8605 & 0.86054 & 28.1 & 0.0003 \\
\hline Ip*P & 1 & 0.0124 & 0.01243 & 0.41 & 0.036 \\
\hline Vg*Ton & 1 & 0.4607 & 0.46069 & 15.04 & 0.002 \\
\hline $\mathrm{Vg} * \mathrm{P}$ & 1 & 0.2283 & 0.22828 & 7.45 & 0.08 \\
\hline Ton*P & 1 & 0.1025 & 0.10249 & 3.35 & 0.002 \\
\hline Error & 12 & 0.3675 & 0.03063 & & \\
\hline Lack-of-Fit & 10 & 0.357 & 0.0357 & 6.79 & 0.135 \\
\hline Pure Error & 2 & 0.0105 & 0.00526 & & \\
\hline Total & 26 & 14.8469 & & & \\
\hline
\end{tabular}

Table 4

Analysis of variance table for TWR

\begin{tabular}{|c|c|c|c|c|c|}
\hline Source & DF & Adj SS & Adj MS & F-Value & P-Value \\
\hline Model & 14 & 14.4794 & 1.03424 & 33.77 & 0.0002 \\
\hline Linear & 4 & 11.5722 & 2.89306 & 94.47 & 0.001 \\
\hline $\mathrm{I}_{\mathrm{p}}$ & 1 & 7.2835 & 7.28347 & 237.83 & 0.002 \\
\hline $\mathrm{Vg}$ & 1 & 1.2743 & 1.2743 & 41.61 & 0.0012 \\
\hline $\mathrm{T}_{\text {on }}$ & 1 & 3.0144 & 3.01442 & 98.43 & 0.0021 \\
\hline $\mathrm{P}$ & 1 & 0.0001 & 0.00006 & 0 & 0.964 \\
\hline Square & 4 & 0.6281 & 0.15702 & 5.13 & 0.012 \\
\hline $\mathrm{I}_{\mathrm{p}} * \mathrm{I}_{\mathrm{p}}$ & 1 & 0.0014 & 0.00135 & 0.04 & 0.0037 \\
\hline $\mathrm{Vg} * \mathrm{Vg}$ & 1 & 0.1337 & 0.13373 & 4.37 & 0.059 \\
\hline $\mathrm{T}_{\text {on }} * \mathrm{~T}_{\text {on }}$ & 1 & 0.0563 & 0.05634 & 1.84 & 0.002 \\
\hline $\mathrm{P} * \mathrm{P}$ & 1 & 0.0078 & 0.00779 & 0.25 & 0.0023 \\
\hline 2-Way Interaction & 6 & 2.2791 & 0.37984 & 12.4 & 0.021 \\
\hline $\mathrm{I}_{\mathrm{p}}^{*} \mathrm{~V}_{\mathrm{g}}$ & 1 & 0.6146 & 0.61463 & 20.07 & 0.001 \\
\hline $\mathrm{I}_{\mathrm{p}} * \mathrm{~T}_{\mathrm{on}}$ & 1 & 0.8605 & 0.86054 & 28.1 & 0.0021 \\
\hline $\mathrm{I}_{\mathrm{p}} * \mathrm{P}$ & 1 & 0.0124 & 0.01243 & 0.41 & 0.0036 \\
\hline $\mathrm{V}_{\mathrm{g}} * \mathrm{~T}_{\text {on }}$ & 1 & 0.4607 & 0.46069 & 15.04 & 0.002 \\
\hline $\mathrm{V}_{\mathrm{g}} * \mathrm{P}$ & 1 & 0.2283 & 0.22828 & 7.45 & 0.018 \\
\hline $\mathrm{T}_{\text {on }} * \mathrm{P}$ & 1 & 0.1025 & 0.10249 & 3.35 & 0.002 \\
\hline Error & 12 & 0.3675 & 0.03063 & & \\
\hline Lack-of-Fit & 10 & 0.357 & 0.0357 & 6.79 & 0.135 \\
\hline Pure Error & 2 & 0.0105 & 0.00526 & & \\
\hline Total & 26 & 14.8469 & & & \\
\hline
\end{tabular}


Table 5

Analysis of variance table for SR

\begin{tabular}{|c|c|c|c|c|c|}
\hline Source & DF & Adj SS & Adj MS & F-Value & P-Value \\
\hline Model & 14 & 0.000043 & 0.000003 & 75.8 & 0.002 \\
\hline Linear & 4 & 0.000037 & 0.000009 & 229.92 & 0.0012 \\
\hline $\mathrm{I}_{\mathrm{p}}$ & 1 & 0.000006 & 0.000006 & 156 & 0.001 \\
\hline $\mathrm{V}_{\mathrm{g}}$ & 1 & 0 & 0 & 3.83 & 0.004 \\
\hline$T_{\text {on }}$ & 1 & 0.00003 & 0.00003 & 754.5 & 0.001 \\
\hline $\mathrm{P}$ & 1 & 0 & 0 & 5.36 & 0.003 \\
\hline Square & 4 & 0.000005 & 0.000001 & 29.32 & 0.001 \\
\hline $\mathrm{I}_{\mathrm{p}} * \mathrm{I}_{\mathrm{p}}$ & 1 & 0.000001 & 0.000001 & 20.74 & 0.001 \\
\hline $\mathrm{V}_{\mathrm{g}} * \mathrm{~V}_{\mathrm{g}}$ & 1 & 0 & 0 & 8.72 & 0.012 \\
\hline $\mathrm{T}_{\text {on }} * \mathrm{~T}_{\text {on }}$ & 1 & 0.000005 & 0.000005 & 114.19 & 0.002 \\
\hline $\mathrm{P} * \mathrm{P}$ & 1 & 0 & 0 & 3.08 & 0.004 \\
\hline 2-Way Interaction & 6 & 0.000001 & 0 & 4.05 & 0.0019 \\
\hline $\mathrm{I}_{\mathrm{p}}^{*} \mathrm{~V}_{\mathrm{g}}$ & 1 & 0 & 0 & 1.82 & 0.002 \\
\hline $\mathrm{I}_{\mathrm{p}} * \mathrm{~T}_{\mathrm{on}}$ & 1 & 0.000001 & 0.000001 & 15.55 & 0.002 \\
\hline $\mathrm{I}_{\mathrm{p}}^{* \mathrm{P}}$ & 1 & 0 & 0.000 & 0.42 & 0.0027 \\
\hline $\mathrm{V}_{\mathrm{g}} * \mathrm{~T}_{\text {on }}$ & 1 & 0 & 0.000 & 0.12 & 0.0037 \\
\hline $\mathrm{V}_{\mathrm{g}} * \mathrm{P}$ & 1 & 0 & 0.000 & 6 & 0.031 \\
\hline $\mathrm{T}_{\text {on }} * \mathrm{P}$ & 1 & 0 & 0.000 & 0.38 & 0.0048 \\
\hline Error & 12 & 0 & 0.000 & & \\
\hline Lack-of-Fit & 10 & 0 & 0.000 & 105.46 & 0.009 \\
\hline Pure Error & 2 & 0 & 0.000 & & \\
\hline Total & 26 & 0.000043 & & & \\
\hline
\end{tabular}

\subsection{Influence of process parameters on surface roughness (SR)}

The high electrical discharge between tool and workpiece produces crater wear on the workpiece surface which introduces poor surface finish. Therefore, it is necessary to predict an optimum set of parameters to produce a machined surface with a good surface finish. In the present work, the impact of process parameters namely, peak current, gap voltage, pulse on time, and flushing pressure is shown with help of 3D surface plots in Fig. 7. From Fig. 7(a), 7(b), and 7 (c), it is observed that the increase in peak current results increase in surface roughness. This may be because the increase in peak current leads to high MRR which results in poor surface finish. It is also observed that the increase in pulse on time and flushing pressure leads to higher values of MRR resulting in high surface roughness. From Fig. 7(d), 7(a), and 7(c), it is observed that the increase in gap voltage along with an increase in peak current, pulse on time, and flushing pressure leads to an increase in surface roughness.

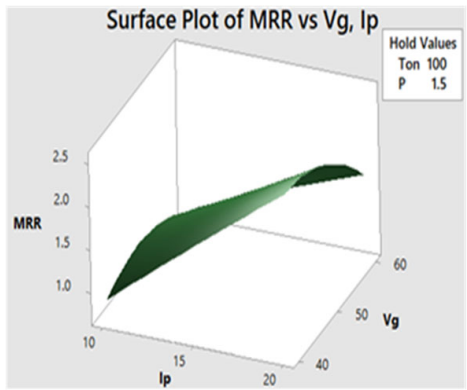

(a)

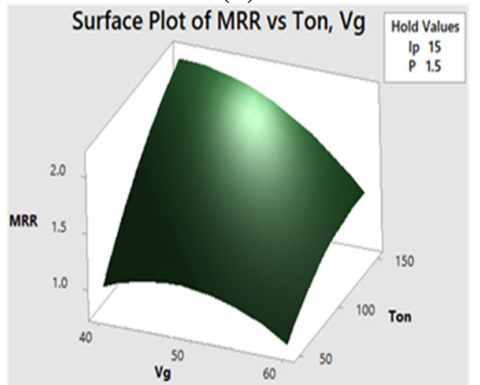

(d)

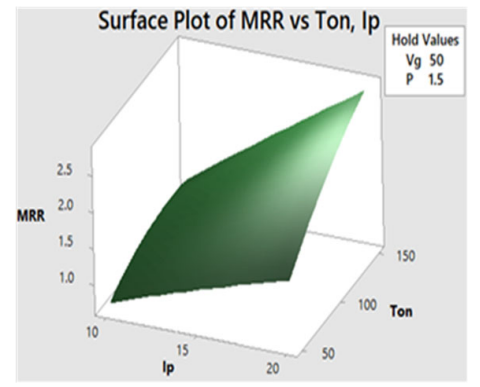

(b)

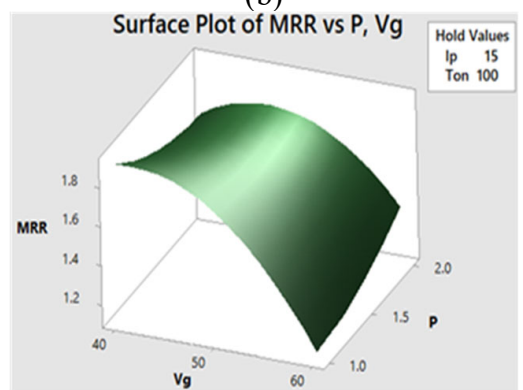

(e)

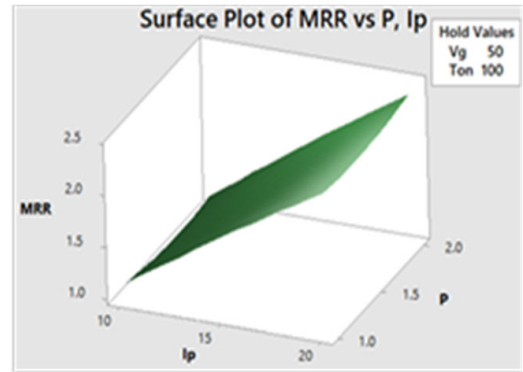

(c)

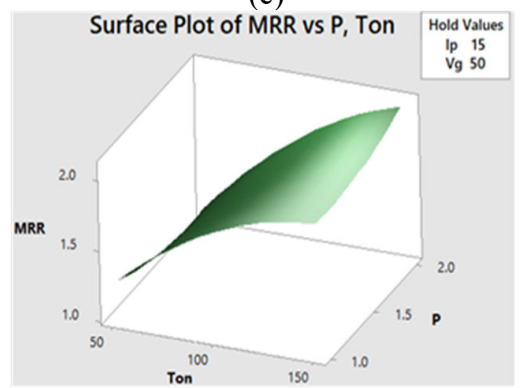

(f)

Fig. 5. 3D response surface plots showing (a) the effect of current and voltage(b) the effect of peak current and pulse on time(c) the effect of peak current and flushing pressure (d) the effect of voltage and pulse on time (e) the effect of gap voltage and flushing pressure (f) the effect of pulse on time \& flushing pressure on material removal rate of Al356/WC MMCs 


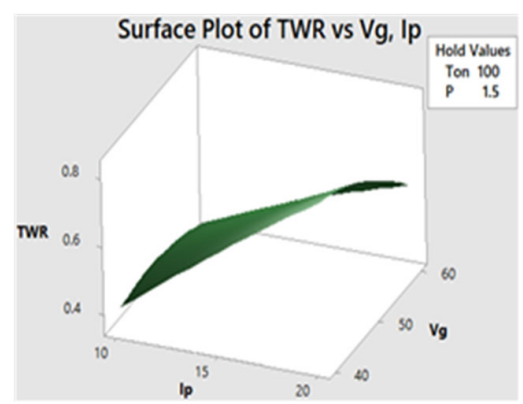

(a)

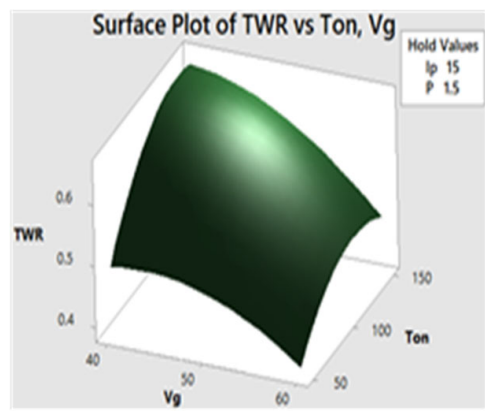

(d)

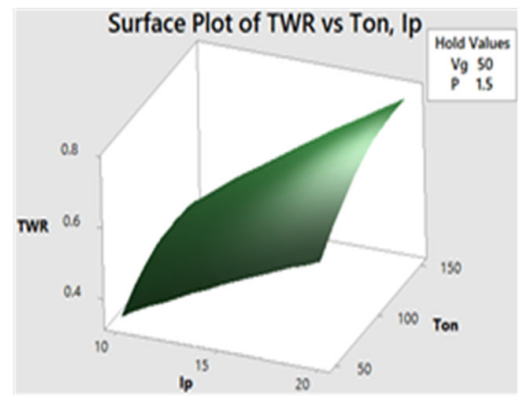

(b)

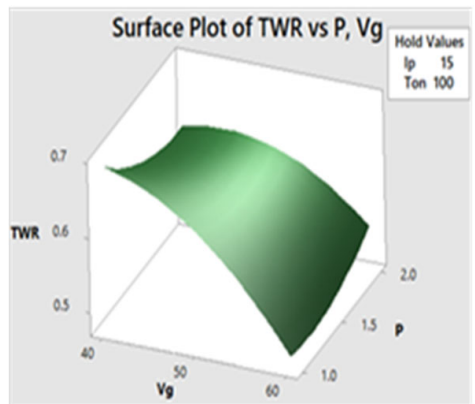

(e)

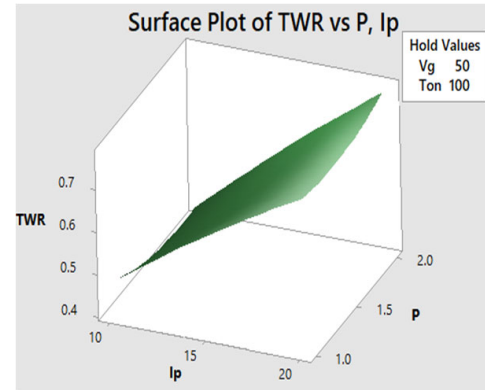

(c)

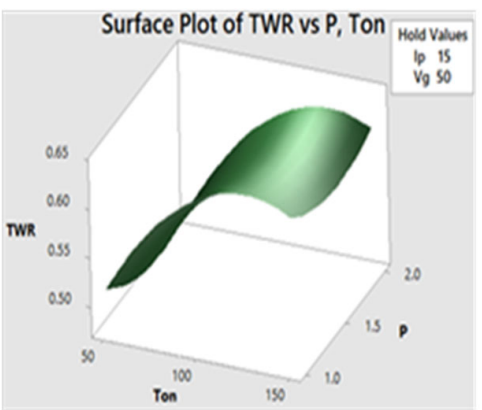

(f)

Fig. 6. 3D response surface plots showing (a) the effect of current and voltage(b) the effect of peak current and pulse on time(c) the effect of peak current and flushing pressure (d) the effect of voltage and pulse on time (e) the effect of gap voltage and flushing pressure (f) the effect of pulse on time \& flushing pressure on the tool wear rate of Al356/WC MMCs

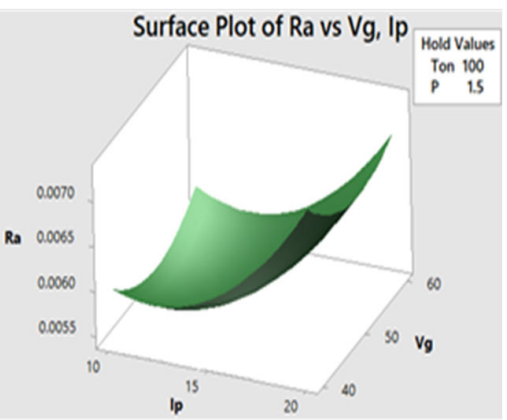

(a)

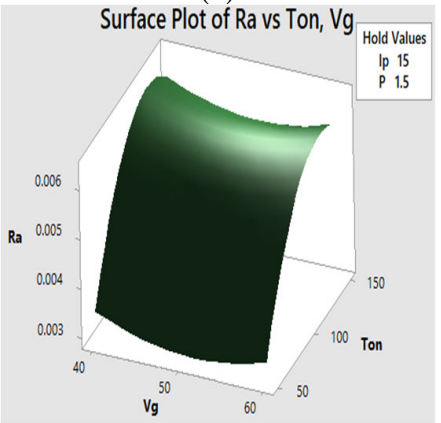

(d)

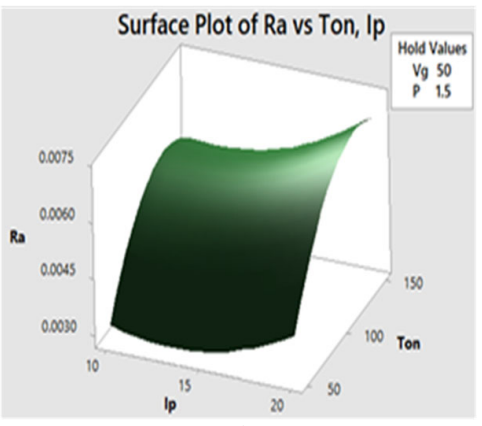

(b)

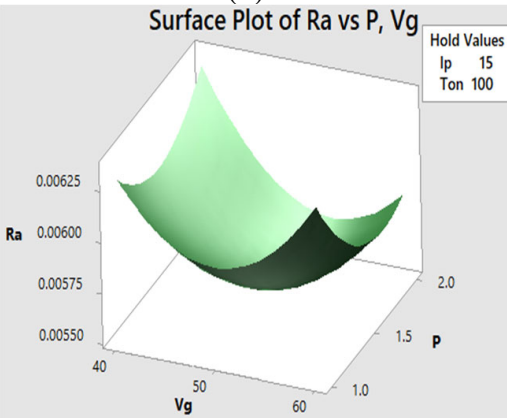

(e)

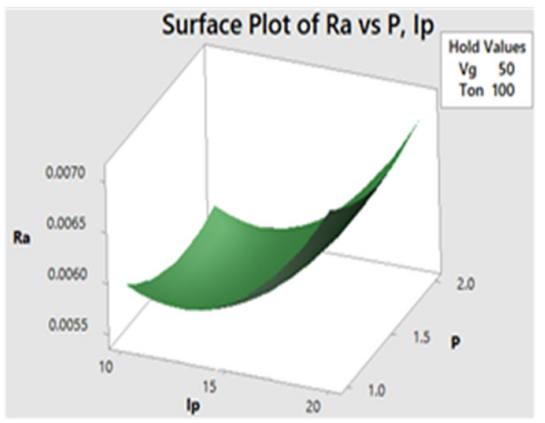

(c)

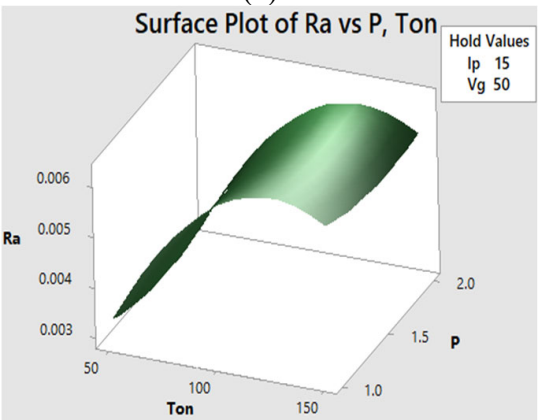

(f)

Fig. 7. 3D response surface plots showing (a) the effect of current and voltage(b) the effect of peak current and pulse on time(c) the effect of peak current and flushing pressure (d) the effect of voltage and pulse on time (e) the effect of gap voltage and flushing pressure (f) the effect of pulse on time \& flushing pressure on surface roughness of Al356/WC MMCs.

\subsection{Regression Model Validation}

The forecast correctness of the established non-linear regression models developed for the electric discharge machining of a356/WC MMCs is tested with the help of ten experimental test scenarios. The graph displaying the percentage deviation 
in estimation of the outcomes MRR, TWR, and ROC are presented in Figs. 7. The range of percentage deviation in the prediction of responses MRR, TWR, and ROC is seen to be equal to $(-9.454$ to +6.375$),(-5.678$ to +6.276$)$, and (-6.629 to +5.252 ) during machining of Al356/WC composite. The range of percentage deviation in the prediction of the responses shows that the regression models have predicted the responses with reasonably good accuracy.

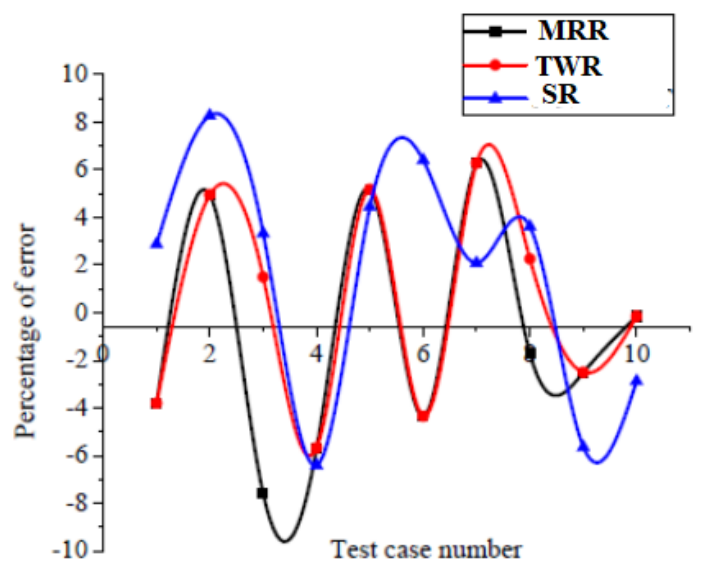

Fig. 8. Graph showing the percentage deviation in prediction of the responses during EDM 3.6 Gray relational analysis

The results related to the multi-objective optimization using GRA during the machining of Al356/WC MMCs are shown in Table 6. The experimental outcomes, deviation sequence, and grey relational code values for the responses namely, MRR, TWR, and SR are given in the said table. It is to be noted that during analysis the response MRR is normalized with the help of larger the best quality characteristic, whereas TWR and SR are normalized using smaller the best criterion. Once the GRC values for various responses corresponding to different experiments are calculated, the GRG for each level of the input process parameter is determined by using Eqn. (8) and presented in Table 7. It is important to note that the largest average GRG values in the response table (ref. Table 7.) for the input parameters represent the optimal levels of the corresponding input variables. Therefore, A1-B3-C1-D3 are seen to be the optimal levels for the input parameters namely, peak current, gap voltage, pulse on time, and flushing pressure, respectively. Table 7 also gives the sequence of the impact of various input variables during EDM of A356/WC MMCs.

Table 6

Experimental values, GRC and GRG of A356/WC MMCs

\begin{tabular}{|c|c|c|c|c|c|c|c|c|c|c|}
\hline $\begin{array}{c}\text { Std } \\
\text { Order }\end{array}$ & $\begin{array}{c}\text { CS } \\
\text { MRR } \\
\end{array}$ & $\begin{array}{c}\text { CS } \\
\text { TWR } \\
\end{array}$ & $\begin{array}{l}\text { CS } \\
\text { Ra } \\
\end{array}$ & $\begin{array}{c}\text { DS } \\
\text { MRR }\end{array}$ & $\begin{array}{c}\text { DS } \\
\text { TWR }\end{array}$ & $\begin{array}{l}\text { DS } \\
\text { Ra } \\
\end{array}$ & $\begin{array}{l}\text { GRC } \\
\text { MRR } \\
\end{array}$ & $\begin{array}{l}\text { GRC } \\
\text { TWR } \\
\end{array}$ & $\begin{array}{c}\text { GRC } \\
\text { Ra } \\
\end{array}$ & GRG \\
\hline 1 & 0.155789 & 0.819406 & 0.80661 & 0.844211 & 0.180594 & 0.19339 & 0.371965 & 0.734652 & 0.721095 & 0.609238 \\
\hline 2 & 0.464403 & 0.399998 & 0.629549 & 0.535597 & 0.600002 & 0.370451 & 0.482813 & 0.454545 & 0.574415 & 0.503924 \\
\hline 3 & 0.046128 & 0.946424 & 0.767263 & 0.953872 & 0.053576 & 0.232737 & 0.343909 & 0.903218 & 0.682373 & 0.643167 \\
\hline 4 & 0.223605 & 0.755093 & 0.668896 & 0.776395 & 0.244907 & 0.331104 & 0.391728 & 0.671225 & 0.60161 & 0.554854 \\
\hline 5 & 0.255236 & 0.732689 & 0.354122 & 0.744764 & 0.267311 & 0.645878 & 0.401682 & 0.651626 & 0.436346 & 0.496552 \\
\hline 6 & 1 & 0 & 0.078694 & $1.64 \mathrm{E}-14$ & 1 & 0.921306 & 1 & 0.333333 & 0.351789 & 0.561707 \\
\hline 7 & 0.097561 & 0.897652 & 0.334448 & 0.902439 & 0.102348 & 0.665552 & 0.356522 & 0.830085 & 0.428981 & 0.538529 \\
\hline 8 & 0.419578 & 0.599997 & 0.039347 & 0.580422 & 0.400003 & 0.960653 & 0.462782 & 0.555554 & 0.342313 & 0.45355 \\
\hline 9 & 0 & 1 & 0.768837 & 1 & 0 & 0.231163 & 0.333333 & 1 & 0.683842 & 0.672392 \\
\hline 10 & 0.321051 & 0.459244 & 0.649223 & 0.678949 & 0.540756 & 0.350777 & 0.424107 & 0.48042 & 0.587698 & 0.497408 \\
\hline 11 & 0.0688 & 0.989095 & 0.885304 & 0.9312 & 0.010905 & 0.114696 & 0.349357 & 0.978656 & 0.81341 & 0.713808 \\
\hline 12 & 0.276533 & 0.614997 & 0.694078 & 0.723467 & 0.385003 & 0.305922 & 0.408675 & 0.56497 & 0.620408 & 0.531351 \\
\hline 13 & 0.229082 & 0.870942 & 0.431635 & 0.770918 & 0.129058 & 0.568365 & 0.393417 & 0.794839 & 0.468005 & 0.552087 \\
\hline 14 & 0.997832 & 0.082894 & 0 & 0.002168 & 0.917106 & 1 & 0.995682 & 0.352832 & 0.333333 & 0.560616 \\
\hline 15 & 0.170817 & 0.86944 & 0.401928 & 0.829183 & 0.13056 & 0.598072 & 0.376171 & 0.792946 & 0.455344 & 0.541487 \\
\hline 16 & 0.573171 & 0.464998 & 0.195751 & 0.426829 & 0.535002 & 0.804249 & 0.539474 & 0.483091 & 0.383362 & 0.468642 \\
\hline 17 & 0.175634 & 0.816888 & 0.491836 & 0.824366 & 0.183112 & 0.508164 & 0.377539 & 0.731944 & 0.495951 & 0.535145 \\
\hline 18 & 0.69677 & 0.275999 & 0.196734 & 0.30323 & 0.724001 & 0.803266 & 0.622487 & 0.408496 & 0.383652 & 0.471545 \\
\hline 19 & 0.384261 & 0.50034 & 0.354122 & 0.615739 & 0.49966 & 0.645878 & 0.448134 & 0.50017 & 0.436346 & 0.46155 \\
\hline 20 & 0.352922 & 0.671997 & 0.413142 & 0.647078 & 0.328003 & 0.586858 & 0.43589 & 0.603862 & 0.460042 & 0.499931 \\
\hline 21 & 0.274526 & 0.679497 & 1 & 0.725474 & 0.320503 & 0 & 0.408006 & 0.609382 & 1 & 0.672463 \\
\hline 22 & 0.515413 & 0.549283 & 0.438127 & 0.484587 & 0.450717 & 0.561873 & 0.507827 & 0.525919 & 0.470866 & 0.501537 \\
\hline 23 & 0.443804 & 0.46406 & 0.393468 & 0.556196 & 0.53594 & 0.606532 & 0.473397 & 0.482654 & 0.451862 & 0.469304 \\
\hline 24 & 0.479993 & 0.533105 & 0.432815 & 0.520007 & 0.466895 & 0.567185 & 0.490192 & 0.517119 & 0.468522 & 0.491945 \\
\hline 25 & 0.473559 & 0.510147 & 0.425536 & 0.526441 & 0.489853 & 0.574464 & 0.48712 & 0.505126 & 0.465348 & 0.485865 \\
\hline 26 & 0.43216 & 0.530997 & 0.432815 & 0.56784 & 0.469003 & 0.567185 & 0.468235 & 0.515994 & 0.468522 & 0.484251 \\
\hline 27 & 0.43216 & 0.557697 & 0.432815 & 0.56784 & 0.442303 & 0.567185 & 0.468235 & 0.530615 & 0.468522 & 0.489124 \\
\hline
\end{tabular}


Table 7

Response table for the Grey relational grade

\begin{tabular}{ccccc}
\hline Levals & Ip & Vg & Ton & P \\
\hline 1 & $\mathbf{0 . 5 8 9 1 5 6}$ & 0.546164 & $\mathbf{0 . 5 9 9 8 4 5}$ & 0.536758 \\
2 & 0.506219 & 0.511242 & 0.487629 & 0.511268 \\
max-min & 0.511511 & $\mathbf{0 . 5 4 9 4 8}$ & 0.519412 & 0.112216 \\
\hline Rank & 0.082937 & 0.038238 & 0.558859 & 1 \\
\hline
\end{tabular}

\subsection{Comparative study of RSM and GRA}

In the present section, a comparative study is made between the optimal values of the input process parameters, and the response values obtained using RSM and GRA are shown in Table 8. From the said table, it has been observed that GRA is found to slightly outperform RSM during machining of A356/WC MMCs using EDM. Even though the RSM optimizer has provided better MRR when compared with GRA, the GRA is found to provide superior performance as it helped in improving the surface texture of the component as well as lower wear rate on the tool. This will provide a more economical solution in the context of the manufacturing system.

Table 8

Experimental values, GRC and GRG of A356/WC MMCs

\begin{tabular}{|c|c|c|c|}
\hline \multirow{2}{*}{\multicolumn{2}{|c|}{ Inputs/Responses }} & \multicolumn{2}{|c|}{ Optimal set of parameters } \\
\hline & & RSM & GRA \\
\hline \multirow{7}{*}{ Input process parameters } & IP & 16.16 & 10 \\
\hline & $\mathrm{Vg}$ & 49.49 & 60 \\
\hline & Ton & 50 & 50 \\
\hline & $\mathrm{P}$ & 1.2222 & 2 \\
\hline & MRR & 1.292 & 0.291 \\
\hline & TWR & 0.581 & 0.549 \\
\hline & SR & 0.0035 & 0.003 \\
\hline
\end{tabular}

\section{Conclusions}

In the present study, an experimental investigation is carried out on A356/WC MMCs using a central composite design of experiments. The optimum set of parameters are obtained with the application of a multi-criterion optimization tool namely Grey regression analysis. From the results, it was observed that the developed non-linear regression models can predict the responses namely MRR, TWR, and SR with a coefficient of co-relation of $97.2 \%, 98.79$, and $98.88 \%$, respectively. Moreover, the validation of regression models also suggests that the prediction accuracy is within the allowable limits. Further, the multi criterion optimization utilizing GRA has provided a better optimal solution than the solution obtained by RSM.

\section{References}

Chandramouli, S., \& Eswaraiah, K. (2017). Optimization of EDM process parameters in machining of 17-4 PH steel using Taguchi method. Materials Today: Proceedings, 4(2), 2040-2047.

Dey, a., pandey, k. M., rai, r. N., khan, a., \& das, a. (2021). Application potential of response surface method on electro discharge machining of aa6061-cenosphere AMCs prepared by compocasting method. Surface review and letters, 2150056.

Dhas, D. E. J., Velmurugan, C., Wins, K. L. D., \& BoopathiRaja, K. P. (2019). Effect of tungsten carbide, silicon carbide and graphite particulates on the mechanical and microstructural characteristics of AA 5052 hybrid composites. Ceramics International, 45(1), 614-621.

Dhupal, D., Naik, S., \& Das, S. R. (2018). Modelling and optimization of Al-SiC MMC through EDM process using copper and brass electrodes. Materials Today: Proceedings, 5(5), 11295-11303.

Dwivedi, S. P., Sharma, S., \& Mishra, R. K. (2014). A356 aluminum alloy and applications-a review. Advanced Materials Manufacturing \& Characterization, 4(2), 81-86.

Jagtap, V. L. (2016). A review of EDM Process for difficult to cut materials. Int Res J Multidiscip Stud, 2, $2454-8499$.

Kandpal, B. C., Kumar, J., \& Singh, H. (2018). Optimisation Of Process Parameters Of Electrical Discharge Machining Of Fabricated AA 6061/10\% A12 O3 Aluminium Based Metal Matrix Composite. Materials Today: Proceedings, 5(2), 4413-4420.

Kandpal, B. C., \& Singh, H. (2015). Machining of aluminium metal matrix composites with electrical discharge machininga review. Materials Today: Proceedings, 2(4-5), 1665-1671.

Kar, C., Surekha, B., Jena, H., \& Choudhury, S. D. (2018). Study of influence of process parameters in electric discharge machining of aluminum-red mud metal matrix composite. Procedia Manufacturing, 20, 392-399. 
Krishna, A. R., Arun, A., Unnikrishnan, D., \& Shankar, K. V. (2018). An investigation on the mechanical and tribological properties of alloy A356 on the addition of WC. Materials Today: Proceedings, 5(5), 12349-12355.

Kumar, G. V., Bai, B. H., \& Venkataramaiah, P. (2018). A Fuzzy approach to trim down the struggles in machining of AMMC by means of optimization of the Surface Roughness and Kerf Width. Materials Today: Proceedings, 5(5), 13236-13243.

Kumar, R. A., Devaraju, A., \& Arunkumar, S. (2018). Experimental investigation on mechanical behaviour and wear parameters of tic and graphite reinforced aluminium hybrid composites. Materials Today: Proceedings, 5(6), 1424414251.

Kumar, S. S., Uthayakumar, M., Kumaran, S. T., Varol, T., \& Canakci, A. (2019). Investigating the surface integrity of aluminium based composites machined by EDM. Defence Technology, 15(3), 338-343.

Kumar, V., Singh, B., Chandel, S., \& Singhal, P. (2020). Evaluation of EDM characteristics of synthesised AA2024-2 \& 3 wt\% SiO2 metal matrix nanocomposite (MMNC). Materials Today: Proceedings, 26, 1449-1454.

Lata, S., Pandey, A., Sharma, A., Meena, K., Rana, R., \& Lal, R. (2018). An experimental study and analysis of the mechanical properties of titanium dioxide reinforced aluminum (AA 5051) composite. Materials Today: Proceedings, 5(2), 6090-6097.

Malhotra, P., Tyagi, R. K., Singh, N. K., \& Sikarwar, B. S. (2020). Experimental investigation and effects of process parameters on EDM of Al7075/SiC composite reinforced with magnesium particles. Materials Today: Proceedings, 21, 1496-1501.

Markopoulos, A. P., Papazoglou, E. L., Svarnias, P., \& Karmiris-Obratański, P. (2019). An Experimental investigation of machining aluminum alloy Al5052 with EDM. Procedia Manufacturing, 41, 787-794.

Niamat, M., Sarfraz, S., Aziz, H., Jahanzaib, M., Shehab, E., Ahmad, W., \& Hussain, S. (2017). Effect of different dielectrics on material removal rate, electrode wear rate and microstructures in EDM. Procedia Cirp, 60, 2-7.

Palanisamy, D., Devaraju, A., Manikandan, N., Balasubramanian, K., \& Arulkirubakaran, D. (2020). Experimental investigation and optimization of process parameters in EDM of aluminium metal matrix composites. Materials Today: Proceedings, 22, 525-530.

Panda, S., Mishra, D., Biswal, B. B., \& Nanda, P. (2015). Optimization of multiple response characteristics of EDM process using taguchi-based grey relational analysis and modified PSO. Journal of Advanced Manufacturing Systems, 14(03), 123-148.

Raju, K., \& Balakrishnan, M. (2020). Experimental study and analysis of operating parameters in wire EDM process of aluminium metal matrix composites. Materials Today: Proceedings, 22, 869-873.

Rohith, K. P., Rajan, E. S., Harilal, H., Jose, K., \& Shankar, K. V. (2018). Study and comparison of A356-WC composite and A356 alloy for an off-road vehicle chassis. Materials Today: Proceedings, 5(11), 25649-25656.

Sakthivelu, S., Sethusundaram, P. P., Meignanamoorthy, M., Kumar, S. D., Chanakyan, C., \& Alagarsamy, S. V. (2020). Prediction of optimum electric discharge machining parameters for AA7075-SiC composites. Materials Today: Proceedings, 27, 1192-1196.

Sharma, A. K., Bhandari, R., Aherwar, A., Rimašauskienė, R., \& Pinca-Bretotean, C. (2020). A study of advancement in application opportunities of aluminum metal matrix composites. Materials Today: Proceedings, 26, $2419-2424$.

Shehata, F., El Mahallawy, N., Abd El Hameed, M., \& Abd El Aal, M. (2006). Effect of kerosene and paraffin oil as dielectrics on the electric discharge machining characteristics of al/sic metal matrix composite. Production Engineering \& Design for Development, PEDD7, Cairo, 10-19.

Shukla, M., \& Dhakad, S. K. (2018). Optimisation of electrical discharge machining of Al-LM-6/SiC/B4C composite: A grey relational approach. Materials Today: Proceedings, 5(9), 19147-19155.

Siddanna, A. \& Devoor, N. S., (2016). Study the microstructure and impact strength of $1 \mathrm{~m} 25$ aluminium alloy reinforced with steel wire. International Research Journal of Engineering and Technology, 03, 614-619.

Srivastava, A. K. (2020). Assessment of mechanical properties and EDM machinability on A16063/SiC MMC produced by stir casting. Materials Today: Proceedings, 25, 630-634.

Talla, G., Sahoo, D. K., Gangopadhyay, S., \& Biswas, C. K. (2015). Modeling and multi-objective optimization of powder mixed electric discharge machining process of aluminum/alumina metal matrix composite. Engineering Science and Technology, an International Journal, 18(3), 369-373.

Tharian, B. K., Jacob, E., Johnson, J., \& Hari, V. (2019). Multi-objective parametric optimization in EDM using grey relational analysis. Materials Today: Proceedings, 16, 1013-1019.

Venkatesan, S., \& Xavior, M. A. (2019). Characterization on aluminum alloy 7050 metal matrix composite reinforced with graphene nanoparticles. Procedia manufacturing, 30, 120-127.

Zhang, Y., Liu, Y., Shen, Y., Ji, R., Li, Z., \& Zheng, C. (2014). Investigation on the influence of the dielectrics on the material removal characteristics of EDM. Journal of Materials Processing Technology, 214(5), 1052-1061. 


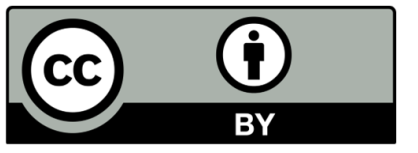

(C) 2022 by the authors; licensee Growing Science, Canada. This is an open access article distributed under the terms and conditions of the Creative Commons Attribution (CC-BY) license (http://creativecommons.org/licenses/by/4.0/). 